SILVEIRA NETO, O.J. et al. Ocorrência e localização de cisticercos em bovinos abatidos e submetidos à Inspeção Federal no Estado de Goiás, Brasil. PUBVET, Londrina, V. 5, N. 21, Ed. 168, Art. 1135, 2011.

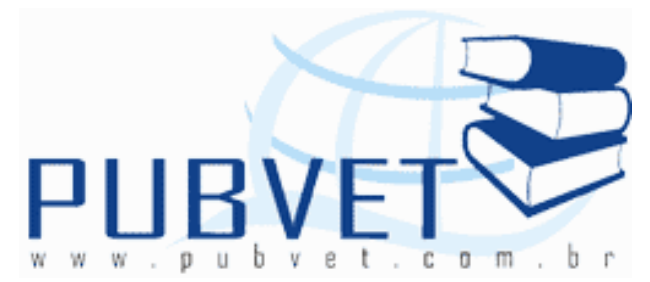

PUBVET, Publicações em Medicina Veterinária e Zootecnia.

\title{
Ocorrência e localização de cisticercos em bovinos abatidos e submetidos à Inspeção Federal no Estado de Goiás, Brasil
}

Osvaldo José da Silveira Netoㄹ; Raphael Rocha de Oliveira²; Fabricio de Oliveira Pereira ${ }^{2}$, Ângelo Leonardo de Castro Basile ${ }^{3}$; Rodrigo Zaiden Taveira ${ }^{4}$

1. Professor da Universidade Estadual de Goiás, Doutorando em Ciência Animal

2. Médico Veterinário, Mestre em Ciência Animal, Fiscal Estadual Agropecuário

3. Professor Faculdades Objetivo e Universidade Estadual de Goiás

4. Professor Dr. Universidade Estadual de Goiás

\section{Resumo}

O complexo teníase-cisticercose em bovinos representa uma grande preocupação devido as perdas econômicas provocadas aos produtores e também ao risco de transmissão da teníase aos humanos. Objetivou-se com este trabalho verificar a ocorrência da cisticercose em bovinos abatidos em um frigorífico com inspeção federal localizado na região de Goiânia, Goiás, Brasil. Foram analisados dados de 354.459 bovinos abatidos no período de janeiro a dezembro de 2008, relativos aos exames pos-mortem diários realizados pelo Serviço de Inspeção no referido período. Submeteram-se os dados à análise, revelando uma ocorrência de $0,70 \%$ para cisticercose bovina. De todos os 2.487 cisticercos encontrados, 1413 estavam localizados nos músculos masseteres e pterigóides $(56,81 \%), 859$ estavam localizados no coração $(34,54 \%), 105$ no fígado $(4,22 \%), 32$ cisticercos no esôfago $(1,29 \%)$ e 05 
SILVEIRA NETO, O.J. et al. Ocorrência e localização de cisticercos em bovinos abatidos e submetidos à Inspeção Federal no Estado de Goiás, Brasil. PUBVET, Londrina, V. 5, N. 21, Ed. 168, Art. 1135, 2011.

cisticercos encontrados localizavam-se no diafragma (0,20\%). Pode concluir que a cisticercose é uma importante causa de condenação de órgãos e carcaças dos bovinos abatidos, devendo-se atentar para a possível presença de teníase humana na população próxima aos animais.

\title{
Occurrence and location of Cysticercus bovis in cattle submitted to Federal Inspection in slaughterhouse in Goias, Brazil.
}

\begin{abstract}
The current study verified the prevalence of bovine cysticercosis in 354.459 bovines slaughtered in the period between January 2008 and December 2008, in a slaughterhouse, in the municipality of Goiânia, Goiás, Brazil that has a Federal Inspection Service. Monthly nosograph maps related to the daily postmortem, created by the Inspection Service during the period, were used. The data was submitted to analysis that revealed a occurrence of $2.487(0,70 \%)$ of bovine cysticercosis. The parasite presented a frequency of $56,81 \%$ in head muscles and $34,54 \%$ in the heart. The cysticercosis is an important cause of organ and carcass condemnation in slaughtered bovines, may indicates the presence of human teniasis in the human population of the area.
\end{abstract}

\section{Introdução}

O complexo teníase-cisticercose representa uma zoonose de grande importância para a saúde pública e para o setor agropecuário em diversos países do mundo. O ser humano é o único hospedeiro definitivo e obrigatório da Taenia saginata, capaz de albergar em seu intestino a forma adulta do cestóide, desenvolvendo a doença denominada teníase. A forma metacestóide (Cysticercus bovis) é encontrada na musculatura e vísceras de bovinos, hospedeiros intermediários do parasita, causando-Ihes a cisticercose (ACHA \& SZYFRES, 2003), representando problemas econômicos para a indústria da carne e riscos para a saúde pública (URQUHART et al., 1998, TAYLOR, 2010). 
SILVEIRA NETO, O.J. et al. Ocorrência e localização de cisticercos em bovinos abatidos e submetidos à Inspeção Federal no Estado de Goiás, Brasil. PUBVET, Londrina, V. 5, N. 21, Ed. 168, Art. 1135, 2011.

A contaminação dos bovinos ocorre através da ingestão de água ou pastagens contaminadas por ovos de Taenia saginata. Atualmente o recurso de maior expressão no controle desta enfermidade é a inspeção de carnes com exame post-mortem criterioso, o julgamento e o destino adequado das carcaças parasitadas. Assim, a inspeção de carne é a medida direta de maior importância na prevenção da teníase, pois apesar de possuir limitações a inspeção de carcaças e vísceras serve como uma advertência precoce do grau de infecção em uma propriedade ou comunidade, identificando as carcaças com infecções intensas e leves (FUKUDA et al., 1998; REY, 2001; SOARES, 2004; SOUZA et al., 2007).

No Brasil, esta zoonose tem sido um fator preocupante para a pecuária bovina devido ao aumento da incidência em diferentes regiões do país, causando perdas econômicas consideráveis, no que se refere aos achados post-mortem, o que resulta em condenações parciais (tratamento pelo frio ou salga) ou totais das carcaças com presença de cisticercos, acatando as recomendações contidas no Regulamento de Inspeção Industrial e Sanitária de Produtos de Origem Animal (RIISPOA) (BRASIL, 1997). Este fato se reflete também na pecuária brasileira, limitando as possibilidades de exportação de carnes, diminuindo o prestígio como país produtor e o valor de seus produtos (FERNANDES \& BUZETTI, 2001; MARQUES et al, 2008).

DORNY \& PRAET (2007) analisaram a situação da T. saginata na Europa e observaram que, apesar da sistemática inspeção de carne, a $T$. saginata persiste, muito embora a infecção por Taenia solium tenha sido erradicada, principalmente devido ao desenvolvimento sócio econômico geral e intensificação dos sistemas de criação de suínos.

Objetivou-se com este trabalho determinar a ocorrência e localização anatômica preferencial de cisticercos encontrados em carcaças de bovinos abatidos e submetidos à inspeção sanitária durante o período de um ano em um frigorífico que possui inspeção federal na região de Goiânia, Goiás. 
SILVEIRA NETO, O.J. et al. Ocorrência e localização de cisticercos em bovinos abatidos e submetidos à Inspeção Federal no Estado de Goiás, Brasil. PUBVET, Londrina, V. 5, N. 21, Ed. 168, Art. 1135, 2011.

\section{Materiais e Métodos}

Foram avaliados 354.459 bovinos abatidos em um frigorífico com Inspeção Federal localizado na região de Goiânia, Goiás. Os animais procediam de diversas regiões do estado de Goiás e foram abatidos no período de 01 de janeiro a 31 de dezembro de 2008. Os animais foram abatidos conforme tecnologia de produção padrão para bovinos. Exames post-mortem de rotina nas linhas de inspeção de bovinos foram realizados conforme determina 0 RIISPOA (Regulamento de Inspeção Industrial e Sanitária de Produtos de Origem Animal) no Artigo 176, Parágrafo $5^{\circ}$, identificando- se a lesão parasitária de cisticercos.

Caso fossem encontrados cisticercos nos animais nas linhas de inspeção, as lesões eram identificadas e as meias-carcaças, juntamente com as vísceras e cabeça eram encaminhadas para o Departamento de Inspeção final (D.I.F), onde eram melhor analisadas pelo Médico Veterinário, conforme procedimentos regulamentares. Os dados eram anotados em papeleta específica do D.I.F.

Com relação aos critérios de julgamento e destinação de carcaças acometidas pela cisticercose, a Legislação Brasileira (BRASIL, 1997) prevê, após cuidadoso exame da rotina de inspeção, basicamente 3 destinos: liberação, condenação e aproveitamento condicional. A condenação total é indicada para casos de infecções generalizadas. A liberação da carcaça in natura é prevista quando for encontrado um único cisto calcificado, após a sua excisão. Nos casos de infecção moderada ou localizada, as carcaças e órgãos afetados podem ser aproveitados, após serem submetidos a um dos seguintes tratamentos: pelo frio, pelo calor e pela salga (NASCIMENTO, 1991; BRASIL, 1997). 
SILVEIRA NETO, O.J. et al. Ocorrência e localização de cisticercos em bovinos abatidos e submetidos à Inspeção Federal no Estado de Goiás, Brasil. PUBVET, Londrina, V. 5, N. 21, Ed. 168, Art. 1135, 2011.

\section{Resultados e Discussão}

Durante o ano de 2008 foram abatidos e inspecionados 354.459 bovinos, registrando-se 2.487 casos de cisticercose, o que corresponde a uma ocorrência geral de 0,70\%. No Estado de Goiás, REIS et al. (1996) observou durante o período de 1979 a 1993 uma freqüência de aproximadamente $1,05 \%$. Esse mesmo autor observou durante o mesmo período no Estado do Mato Grosso uma freqüência de $0,44 \%$. Mesmo resultado foi observado por Fernandes et al. (2002) que encontraram uma freqüência de 0,42\%. A freqüência da cisticercose varia de acordo com uma série de fatores. Entre eles destacam-se as áreas geográficas do mundo, os meses em que os dados foram mensurados, a localização dos cistos nos músculos e órgãos (UNGAR, 1992).

A distribuição dos cisticercos encontrados na rotina de inspeção foi a seguinte: foram encontrados 2.487 cisticercos, 1413 estavam localizados nos músculos da cabeça (masseteres e pterigóides), correspondendo a 56,81\% do total, 859 estavam localizados no coração, representando $34,54 \%$ do total de ocorrências. Essas duas regiões anatômicas juntas foram responsáveis por 91,35\% do total de ocorrências, assim como citado por SOUZA et al., (2007). As outras regiões acometidas foram o fígado com 105 cisticercos (4,22\%), esôfago: 32 cisticercos (1,29\%) e o diafragma: 05 cisticercos encontrados $(0,20 \%)$. As outras ocorrências de cisticercos foram correspondentes a mais de um cisticerco encontrado, sendo mais de uma região anatômica acometida em um mesmo animal. Quando se analisa a prevalência dessa patologia bovina por região anatômica, encontram-se relatos de diferentes taxas de infecção, de acordo com os órgãos avaliados, período estudado ou região geográfica estudada (SANTOS, 1993; SOARES, 2004; FUKUDA et al., 1998; SOUZA, 2007).

A capacidade de se detectar todos os cisticercos pela rotina de inspeção adotada ainda é motivo de questionamentos. Segundo FUKUDA et al. (1998), a inspeção post mortem baseada em cortes nos tecidos de preferência é pouco eficaz, e em muitos casos de infecção leve pode não detectar os cisticercos, 
SILVEIRA NETO, O.J. et al. Ocorrência e localização de cisticercos em bovinos abatidos e submetidos à Inspeção Federal no Estado de Goiás, Brasil. PUBVET, Londrina, V. 5, N. 21, Ed. 168, Art. 1135, 2011.

pois, por razões de natureza estética e comercial, o inspetor normalmente não retalha todos os órgãos, vísceras e carcaças submetidas à inspeção de rotina. Este fato é confirmado por SANTOS (1993), que comparou o número de cisticercos detectados pelos procedimentos normais de rotina, com o número de cisticercos evidenciados por minucioso fatiamento dessas mesmas porções e de outras não rotineiramente examinadas em carcaças. Constatou-se que nos procedimentos normais de rotina de inspeção não foi possível detectar de 26,0 a $56,7 \%$ dos animais infectados em relação aos casos pesquisados. Neste contexto, SANTOS (1993) enfatizam que quanto mais leve o grau de infecção, maior a possibilidade de não detecção de cisticercos pelos procedimentos normais de rotina de inspeção.

As divergências encontradas nos relatos dos diversos autores sobre a distribuição dos cisticercos nos locais de maior ocorrência podem ser devido a alguns fatores, como a não padronização das técnicas; tendência a examinar com precisão algumas regiões ou vísceras específicas; diferenças nas idades dos animais abatidos assim como o sistema de criação de bovinos (SANTOS, 1993, QUEIROZ et al. 2000).

Apesar das limitações, na maioria dos países a inspeção de carnes é a única medida rotineiramente aplicada no controle e prevenção do complexo teníase - cisticercose (FUKUDA et al. 1998; UNGAR et al., 2001).

\section{Conclusões}

De acordo com os dados obtidos no estudo em questão, pode se comprovar que a prevalência da cisticercose bovina avaliada foi de 0,70\%, mostrando que apesar de apresentar uma prevalência baixa em relação a outros estados, ainda é uma enfermidade presente em bovinos abatidos no estado de Goiás. Pode-se concluir também que as regiões anatômicas de maior ocorrência de cisticercos em bovinos são os músculos da cabeça e o coração, assim como já citado por diversos autores. 


\section{REFERÊNCIAS BIBLIOGRÁFICAS}

1. ACHA, P. N.; SZYFRES, B. Zoonoses and communicable diseases commom to man and animais. Washington: OPAS, 2003. 544p.

2. BRASIL. MINISTÉRIO DA AGRICULTURA. Regulamento da Inspeção Industrial e Sanitária de Produtos de Origem Animal. Aprovado pelo Decreto 30.691 de 29-0352, alterado pelos Decretos 1.255 de 25-06-62, 1.236 de 02-09-94, 1.812 de 08-02-96 e 2.244 de 04-06-97. Brasília, 1997. 174p.

3. DORNY, P.; PRAET, N. Taenia saginata in Europe. Veterinary Parasitology, n. 149, v. 1-2, p. 22-24, 2007.

4. FERNANDES, J.O.M.; BUZETTI, W.A.S. Prevalência de cisticercose bovina em animais abatidos em frigoríficos sob Inspeção Federal, da $9^{a}$ região administrativa de Araçatuba, SP. Higiene Alimentar, vol. 15, p.30-37, 2001.

5. FERnANDES, J. O. M.; SILVA, C. L. S. P.; BORGES, J. H. R.; PEGAIANE, J. C.; COELHO, R. V. Prevalência da cisticercose bovina em animais abatidos em estabelecimento sob regime de Inspeção Federal no município de Andradina-SP. Revista Ciências Agrárias e da Saúde, v. 2, n. 1, p. 14-17, 2002.

6. FUKUDA, R.T.; SANTOS, F.; ANDRADE, C.R. Estudo comparativo entre técnicas de inspeção do diafragma para o diagnóstico da Cisticercose bovina. Higiene Alimentar, v. 12 , n. 55, p. 51-62, 1998.

7. MARQUES, M.G.; BUZI, K.A.; GALINDO, L.A.; BALDINI, E.D.; BIONDI, G.F. Avaliação dos registros de condenação por cisticercose em bovinos abatidos em frigoríficos da região centro-oeste do estado de São Paulo 1996-2000. Veterinária e Zootecnia, v.15, n.1, p. 114-120. 2008.

8. nASCIMENTO, E. Teníase e Cisticercose. In: NEVES, D.P. Parasitologia Humana. 8. ed. São Paulo. Editora Atheneu, p. 230-242, 1991.

9. QUEIROZ, R.P.V., SANTOS, W.L.M., BARBOSA, H.V., SOUZA, R.M., SANTOS FILHO, A.M.P. A importância do diagnóstico da cisticercose bovina. Higiene Alimentar, v.11, n.77, p.12-15, 2000.

10. REIS, D. O.; MUNDIM, M. J. S.; CABRAL, D. D.; CRUZ, J. M. C. Cisticercose bovina: 15 anos de ocorrência em animais abatidos em Uberlândia, 1979 a 1993. Higiene Alimentar, v. 10, n. 43, p. 33-35, 1996.

11. REY, L. Parasitologia - parasitos e doenças parasitárias do homem nas Américas e na África. 3 ed. Rio de Janeiro : Guanabara Koogan, p.731, 2001.

12. SANTOS, I.F. Um modelo de inspeção para a detecção da cisticercose muscular bovina em matadouros. 1993. 73 f. Tese (Livre Docência) - Faculdade de Veterinária. Universidade Federal Fluminense. Niterói, 1993.

13. SOARES, V.E. Infecção experimental de bovinos com ovos de Taenia saginata (Goeze, 1782): distribuição corpórea e alternativas terapêuticas. 2004, 94 f. Tese (Doutorado) - Universidade Estadual Paulista Julio de Mesquita Filho. Jaboticabal, 2004. 
14. SOUZA, V.; PESSOA-SILVA, M.C.; KOWALCZUK, M.; MARTY, S.; SOCCOL, V.T. Regiões Anatômicas de maior Ocorrência de Cysticercus bovis em bovinos submetidos a inspeção federal em matadouro- -frigorífico no município de São José Dos Pinhais, Paraná, de julho a dezembro de 2000. Revista Brasileira de Parasitologia Veterinária, n. 16, v. 2, p. 92-96, 2007.

15.TAYLOR, M.A.; COOP, R.L.; WALL, R.L.. Parasitologia Veterinaria, 3 ed. Rio de Janeiro: Guanabara Koogan. 2010. 742 p.

16. UNGAR, M.L., GERMANO, M.I.S., GERMANO, P.M.L. Cisticercose Bovina. In: GERMANO, P.M.L.; GERMANO, M.I.S. Higiene e Vigilância Sanitária de Alimentos. 2.ed. São Paulo: Livraria Varela, p.335-343, 2001.

17. UNGAR, M. L. Prevalência da cisticercose bovina no estado de São Paulo (Brasil). Revista de Saúde Pública, v. 26, n. 3, p. 1-12, 1992.

18. URQUHART, G.M.; ARMOUR, J.; DUNCAN, J.L.; DUNN, A.M.; JENNINGS, F.W. Parasitologia Veterinária. 2. ed. Rio de Janeiro:Guanabara Koogan, 1998. 273p. 